\title{
Reproductive and Developmental Toxicity of Triclosan (TCN) in Wistar Rats
}

\author{
Malashetty VB'*, Biradar PM$^{2}$, Deshpande $\mathbf{R}^{3}$, \\ Hegde SS ${ }^{1}$ and Nagabhushan $\mathrm{C}^{1}$ \\ ${ }^{1}$ Department of Studies in Zoology, Vijayanagara Sri \\ Krishnadevaraya University, Ballari, India \\ ${ }^{2}$ Department of Zoology, Karnataka University, Dharwad, \\ India \\ ${ }^{3}$ H.K.E.S's Matoshree Taradevi Rampure Institute of \\ Pharmaceutical Sciences, Kalaburagi, Karnataka, India \\ *Corresponding author: Vijaykumar B Malashetty, \\ Professor, Department of Studies in Zoology, \\ Vijayanagara Sri Krishnadevaraya University, \\ Ballari-583105, India
}

Received: August 09, 2021; Accepted: September 07, 2021; Published: September 14, 2021

\begin{abstract}
Triclosan (TCN) was evaluated for reproductive and developmental toxicity on male and female reproductive performance such as gonadal function, mating behaviour, conception, development of the conceptus and parturition. Wistar rats (10/sex/dose) were administered by oral gavage at the dose levels of 0 , 25,75 and $150 \mathrm{mg} / \mathrm{kg}$ bwt/day, prior to mating, during mating and post-mating periods (for males), during pregnancy and up to lactation day 13 (for females). The results showed that, no treatment related mortality or clinical signs. Body weight, food consumption, pre-coital time, gestation length, mating and fertility parameters, percentage of pre- and post-implantation losses, anogenital distance, anogenital ratio were not affected by the treatment. The male pups did not exhibit areola/nipple retention on postnatal day 13. Treatment resulted in significantly lower mean litter size, mean viable litter size and mean number of implantations at $150 \mathrm{mg} / \mathrm{kg}$ bwt/day. The Thyroid Stimulating Hormone (TSH) and Thyroxine (T4) levels in adult rats and pups were not affected. External evaluation of pups as well as gross and microscopic examination of the reproductive organs of the parent animals revealed no adverse triclosan related changes. Considering the changes observed in the mean litter size, mean viable litter size, mean number of implantations and Day 4 surviva index at 150mg/ kg bwt/day, the No Observed Adverse Effect Level (NOAEL)" for reproductive toxicity is considered to be $75 \mathrm{mg} / \mathrm{kg} \mathrm{Bwt} /$ day.
\end{abstract}

Keywords: Triclosan; Reproductive toxicity; Fertility; Pre-implantation loss; Post-implantation loss; Anogenital distance; Thyroid stimulating hormone

\section{Introduction}

Triclosan (2,4,4'-trichloro-2'-hydroxy-diphenyl ether), a broadspectrum antibacterial and antimicrobial chemical and widely used in personal care products (tooth paste, antimicrobial soap, skin cream), daily consumer products (clothes, plastic kitchenware, sports shoes and socks), medical supplies (dental care, medical preservatives and bactericides) and house hold cleaning products such as household detergents, disinfectants [1,2]. TCS is also known and sold as commercial names of Irgasan, DP300, FAT 80'023, CH 3565 and GP 41-353 [3]. Triclosan enters bacterial cells and affects the cytoplasmic membrane and synthesis of RNA, fatty acids, and proteins [1]. Triclosan based hand sanitizers are using very commonly to reduce the transmission of COVID-19 [4]. In 2008, the Environmental Working Group reported finding triclosan in more than 140 types of personal care and home products [5]. Presently, triclosan is one of the contaminants in aquatic and global environments [6]. Data from the 2003-2004 National Health and Nutrition Examination Survey showed triclosan in $75 \%$ of urine samples analyzed [7]. Information about the known commercial uses of triclosan indicates that ingestion and dermal absorption are the most likely routes of exposure [8,9]. Previous reported findings showed (anti) androgenic effects of triclosan in male rats [10], abortion and decline in estrogen sulfotransferase activity in mice [11] and triclosan found in breast milk of humans [12-14]. American researchers published 2517 urine samples of volunteers, of which the concentration of TCS was about 2.4-3790 ng/mL. The plasma TCS concentration of lactating mothers using TCS products was $0.4-38.0 \mathrm{ng} / \mathrm{g}$, and that of breast milk was 0.022-0.95 ng/g during a biomonitoring study [15-20], but it was quickly eliminated primarily in the urine with a mean excretion half-life of $11 \mathrm{hr}$, with no accumulation [21-25]. A study by Park et al. (2019) [26] reported that the concentration of TCS in urine increases with the frequency of use of personal care products in Korea. Despite a short half-life, serious concerns have been raised regarding the toxicity of TCS. TCS in toothpaste, soap, and cosmetics may accumulate in the body, which could have an adverse effect on thyroid hormones and genitalia, and increase the risk of developing breast cancer. Animal studies have shown that TCS adversely affects endocrine function, thyroid hormone homeostasis, and antibiotic resistance [27-32]. In Health Canada [33], overall toxicological database survey showed that TCS ingestion induced liver toxicity in rodents and dogs, and mice were the most sensitive species to TCS toxicity. According to the HC report, rodentspecific metabolism of TCS resulted in a modest decrease in serum thyroxine (T4) levels in rats due to target organ (liver) damage.

TCS exposure showed effects on the pregnancy outcome of pregnant rats. The pregnant rats had abnormal feeding and weight gain ability, blood sugar, serum malondialdehyde, serum protein and other indicators. The composition of live fetus and absorbed fetus of pregnant rats also changed [34]. After short-term intake of TCS in male mice, TCS was detected in testis, epididymis and prostate. It was found that TCS tended to accumulate in epididymis, showing a significantly longer half-life and accumulation time. High dose of 
TCS $(200 \mathrm{mg} / \mathrm{kg}$ ) was also shown to reduce sperm production and cause sperm malformation in rats [35]. A short time exposure to TCS in male rats indicated that the expression levels of several important proteins such as testosterone emergency monitoring protein, androgen receptor and so on were significantly decreased. The levels of luteinizing hormone, follicle stimulating hormone, cholesterol, progesterone and testosterone in serum were significantly decreased, showing a significant impact on sex hormones [36]. It may threaten the health of human offspring if the mother is exposed to triclosan during pregnancy. No data is available on the reproductive and developmental toxicity of triclosan in rats. However, detailed studies are required to ensure its safe use. Hence, the present study is aimed to detailed reproductive/developmental toxicity performance in Wistar rats as per OECD Test Guideline No. 421 [37].

\section{Materials and Methods}

\section{Test chemical}

Triclosan, white crystalline powder, was obtained from SigmaAldrich Chemical Private Limited, Bengaluru, India.

\section{Animals}

Wistar rats, approximately 11 weeks old were obtained from Hylasco Biotechnology Private Limited, Hyderabad and acclimatized for five days before start of the treatment. The animal experiment was performed in accordance with the guideline for care and use of laboratory animals [38]. All experimental protocols were approved by the Institutional Animal Ethics Committee (IAEC) of Karnataka University, Dharwad, Karnataka, India (CPCSEA regd. no.: 639/GO/ Re/S/02/CPCSEA).

\section{Housing, bedding, diet and water}

During mating, two rats of same sex were housed per cage in sterilized polysulfone cages with corncob bedding material. During mating, two rats (one male and one female) were housed and during post-mating, males were housed with their former cage mates while pregnant females were housed individually. Rats were housed in an environment controlled room (temperature: $21 \pm 3{ }^{\circ} \mathrm{C}$ with relative humidity between 58 and 67\%; 12 hours light and 12 hours dark cycle). The sterilized paper shreds were provided on gestation day 20 as nesting material. Pelleted rodent feed (Hindustan Animal Feeds, Gujarat, India) and purified water in polycarbonate bottles were provided ad libitum.

\section{Dosing}

The vehicle used in preparation of the test chemical formulations and for administration to the control group was corn oil. Triclosan was dissolved in corn oil and administered to the rats by oral gavage at dose levels of 25, 75 and $150 \mathrm{mg} / \mathrm{kg}$ bwt/day. Dose formulations were prepared fresh daily prior to administration. Male rats were administered 14 days prior to mating and continued during mating period and until sacrifice. Female rats were administered 14 days prior to the mating and continued through mating, pregnancy and up to lactation day 13. All animals were dosed at approximately the same time each day. Doses were selected based on the previous 14-day repeated dose toxicity study conducted with triclosan in Wistar rats.

\section{Mating procedure}

Females were placed with a single male from the same group in a 1:1 ratio until there was evidence of sperms in the vaginal smear and/or vaginal plug. The day of confirmed mating was designated as gestation day 0 . The pre-coital time was calculated for each female.

\section{Experimental design}

A graphical representation of the experimental design is presented in Table 1. A total of 40 male and 40 female rats were weighed and stratified in ascending order and allocated to four groups of 10 rats/ sex/group. The females showed regular 4-5 days oestrous cyclicity were selected for the study. The study was conducted using four groups of Wistar rats, three treatment groups: 25 (low dose), 75 (mid dose) and 150 (high dose) $\mathrm{mg} / \mathrm{kg}$ bwt/day and a vehicle control (corn oil) treated group with a dose volume of $5 \mathrm{~mL} / \mathrm{kg}$ Bwt. Study specific end points were presented below.

All rats were observed daily for clinical signs of toxicity before dosing and approximately $3 \mathrm{~h}$ after dosing. Detailed clinical examination was conducted prior to the first administration on day 1 and at weekly intervals for all animals. Vaginal smear was examined in females during 14 days pre-mating period to examine the oestrous cyclicity.

Males: The body weights of males were recorded at weekly intervals and food consumption was measured at weekly intervals during the pre-mating period and post-mating period. After four weeks of treatment period, all male rats were fasted overnight (water allowed) and blood was collected from the retro-orbital sinus of rats following isoflurane anesthesia prior to necropsy for thyroid hormone (T4 and TSH) analysis. The animals were subjected to detailed necropsy and testes, epididymides, thyroid with parathyroids, prostate, seminal vesicles and coagulating glands were collected and fixed in neutral buffered $10 \%$ formalin with the exception of testes, which was fixed in Modified Davidson's Solution for histopathological evaluation.

Females: The females were weighed at weekly intervals thereafter

Table 1: A graphical representation of experimental design.

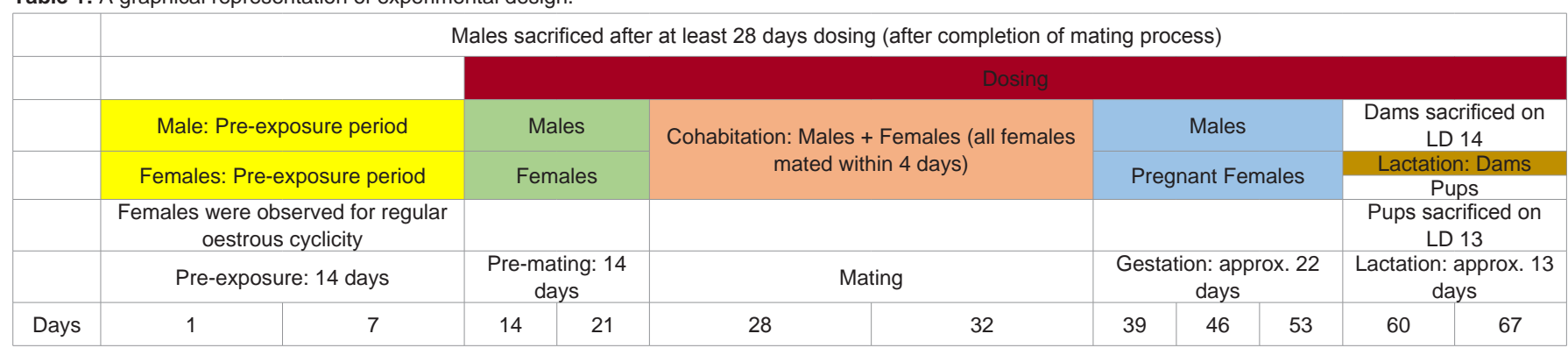


until cohabitation. Dams were weighed on gestation days $0,7,14$ and 20 and during lactation days 0,4 and 13 . Food consumption was measured at weekly intervals during the premating period and for dams were recorded on gestation days 7, 14 and 20 and on lactation days 4 and 13. On lactation day 14, all dams were fasted overnight (water allowed) and blood was collected from the retro-orbital sinus of rats following isoflurane anesthesia prior to necropsy for thyroid hormone (T4 and TSH) analysis. The animals were subjected to detailed necropsy at sacrifice and ovaries, oviducts, uterus, cervix and vagina were collected for histopathological evaluation. The number of implantation sites and corpora lutea were recorded from all the dams.

Litters: All the pups (both dead and alive) in a litter from each dam were observed for external deformities on birth. The number of pups born (litter size), sex and individual pup body weight of male and female pups on lactation days 0,4 and 13 were recorded. After standardization to four pups per sex per litter on lactation 4 , blood samples were collected from surplus pups of either sex for the determination of serum T4 and TSH levels. The number, weight, survival and mortality of pups were observed during the lactation period. The anogenital distance (distance from the caudal margin of the anus to the caudal margin of the genital tubercle) of each pup was measured on lactation day 4 . All the survived male pups were examined for the appearance nipples/areolae on post-natal day (PND 13) [39]. All the surviving pups were sacrificed on lactation day 13 and thyroid gland from available one male and one female pup from each litter was collected for histopathological examination. Fertility index for dams, sires as well as the pup survival index until lactation day 4 were calculated.

\section{Statistical analysis}

All quantitative variables like body weight, food consumption, estrous cycle length, anogenital distance were tested for normality [40] and homogeneity of variances [41] within the group before performing a one-factor Analysis of Variance (ANOVA) modelling by treatment groups. Comparison of means between treatment groups and control group was done using Dunnett's test. Postimplantation loss (\%), number of nipples/areolae in male pups, number of implantations, pre-coital interval, mean litter size, sex ratio and gestation length was analysed after suitable transformation $(\sqrt{ } x+1 / 2)$ of the data. Dunnett's pair-wise comparison of the treated means with the control mean was done when the group differences are found significant. ' $Z$ ' test was performed for testing the differences in proportions for mating and fertility indices. A difference was considered statistically significant at $\mathrm{p} \leq 0.05$.

\section{Results and Discussion}

\section{Detailed Clinical Examination, Clinical signs and mortality}

No triclosan related clinical signs and mortality was observed in the animals throughout the experiment. However, clinical sign of sparse hair loss at right and left flank was observed in a female of control group and one male rat of high dose group was considered spontaneous finding and not related to treatment.

\section{Body weights and food consumption}

The mean body weight and food consumption between the triclosan treated and control groups were comparable in males during pre-mating, mating and post-mating period and in females

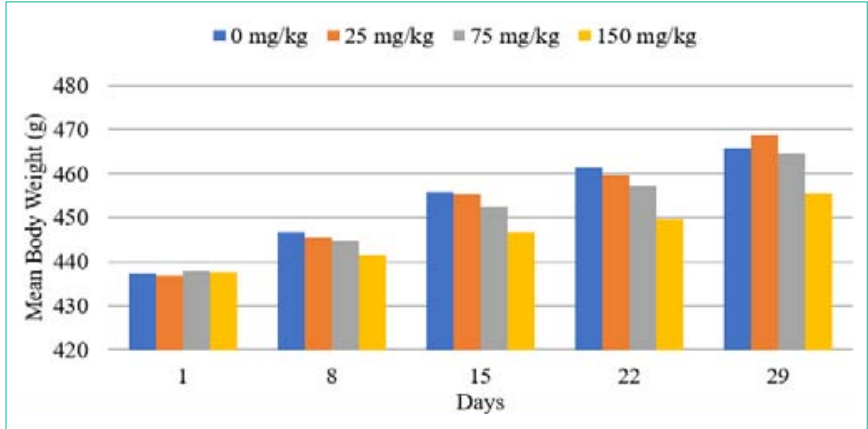

Figure 1: Mean body weights of male rats during pre-mating, mating and post-mating period.

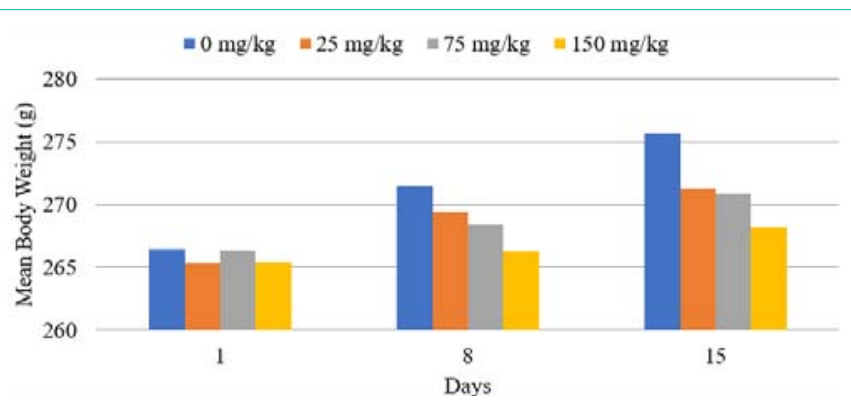

Figure 2: Mean body weight of female rats during pre-mating period.

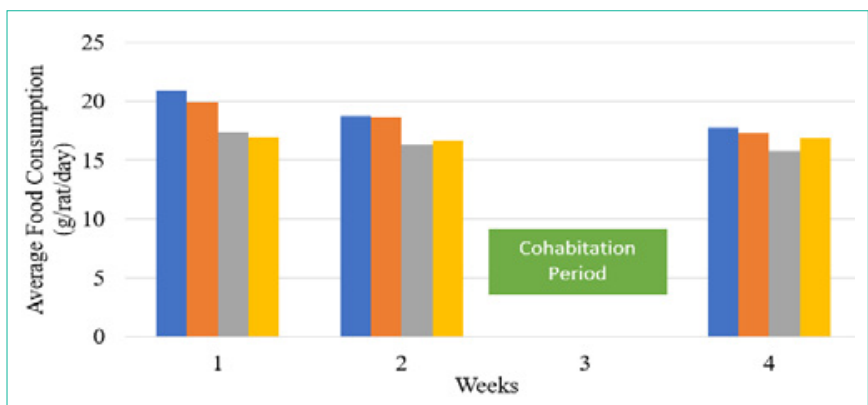

Figure 3: Food consumption of male rats.

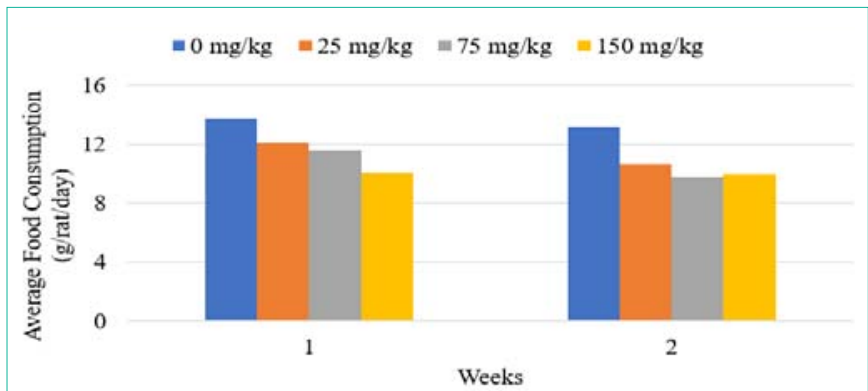

Figure 4: Food consumption of female rats during pre-mating period.

during pre-mating period (Figure 1-4).

This result is consistent with those observed in Wistar rats (around 10 weeks old) orally treated with TCS, for 60 days, at doses of 5,10 , and $20 \mathrm{mg} / \mathrm{kg}$ [42].

\section{Estrous cycle evaluation}

The treatment did not affect the mean oestrous cycle length. The calculated mean oestrous cycle length was $4.08,4.07,4.11$ and 4.18 


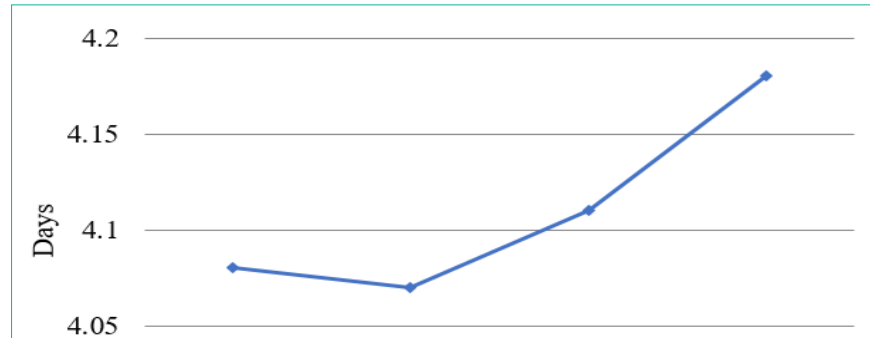

$0 \mathrm{mg} / \mathrm{kg} \quad 25 \mathrm{mg} / \mathrm{kg} \quad 75 \mathrm{mg} / \mathrm{kg} \quad 150 \mathrm{mg} / \mathrm{kg}$

Figure 5: Mean oestrous cycle length during pre-mating period.

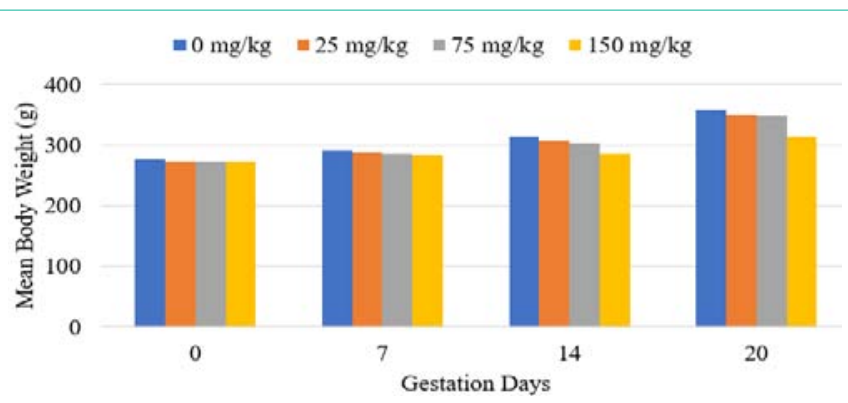

Figure 6: Mean body weight of female rats during gestation periods.

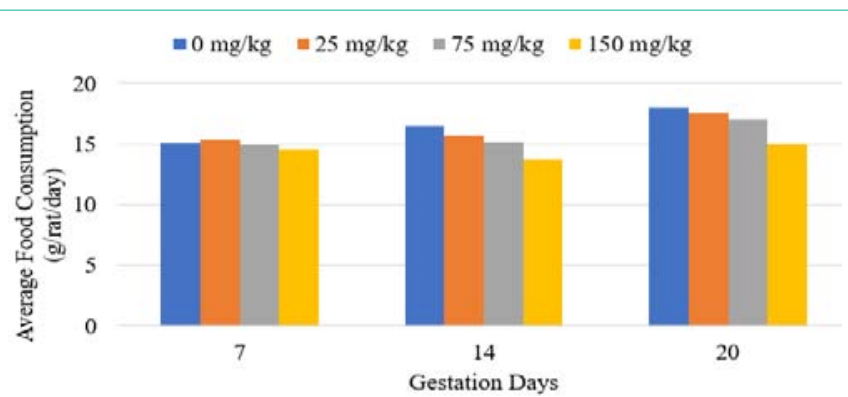

Figure 7: Food consumption of female rats during gestation periods.

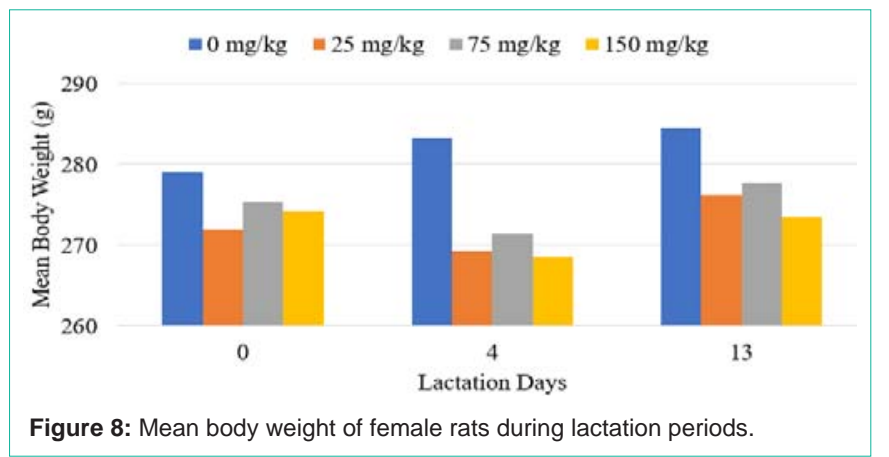

days in vehicle control, 25, 75 and $150 \mathrm{mg} / \mathrm{kg}$ Bwt/day dose groups, respectively. The mean oestrous cycle length in the treated groups was not significantly different from the vehicle control group (Figure 5).

\section{Maternal body weight and food consumption during gestation and lactation period}

During gestation and lactation, the mean maternal body weights and average daily food consumption was not affected at any of the

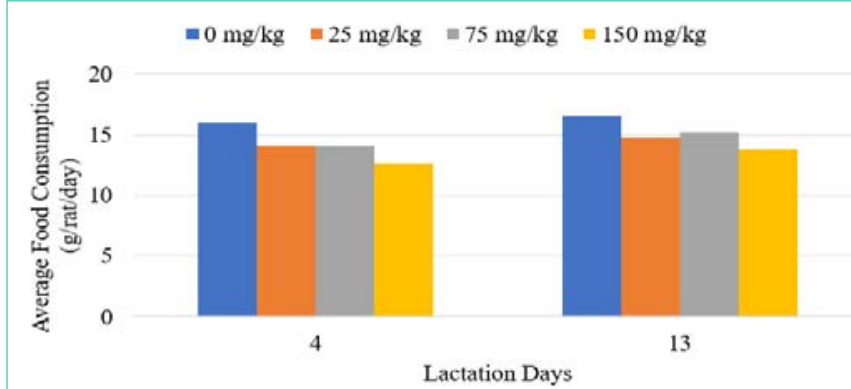

Figure 9: Food consumption of female rats during lactation periods.

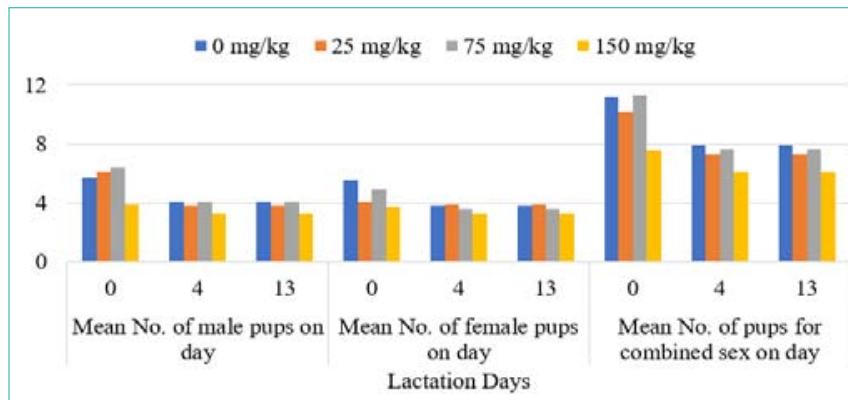

Figure 10: Mean number of male, female and total pups during lactation period

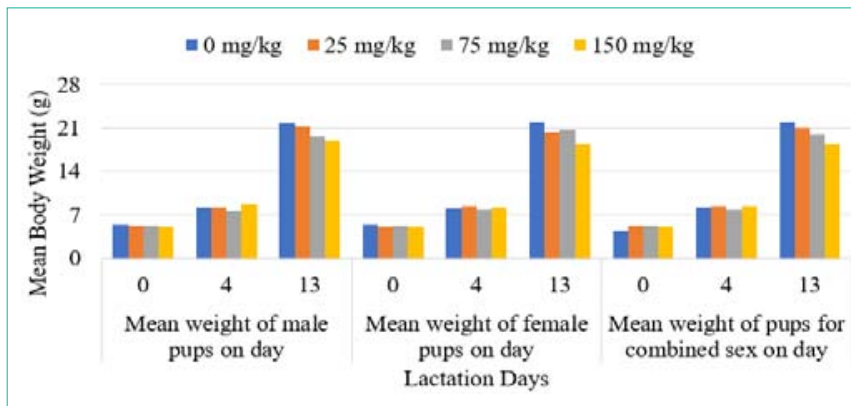

Figure 11: Mean weight of male, female and total pups during lactation period

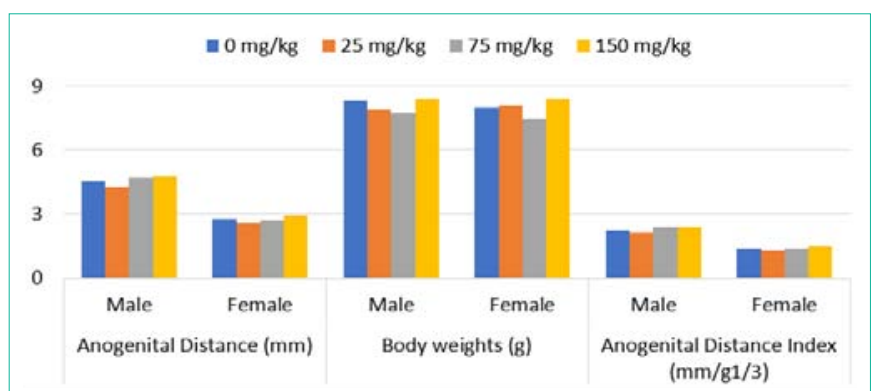

Figure 12: Measurement of anogenital distance of male and female pups.

doses tested, when compared to vehicle control (Figure 6-9).

Number and body weight of pups during lactation period

The mean number and weight of male, female and total pups per litter were unaffected by the treatment (Figure 10 and 11).

\section{Anogenital distance}

No changes were observed in the AGD and ratio of AGD to 
Table 2: Summary of survival data of pups and fertility index.

\begin{tabular}{|c|c|c|c|c|c|}
\hline \multirow{3}{*}{ Particulars } & Group & G1 & G2 & G3 & G4 \\
\hline & Dose (mg/kg Bwt/day) & 0 & 25 & 75 & 150 \\
\hline & No. of Dams & 10 & 10 & 10 & 10 \\
\hline No. of pregnancies & & 10 & 10 & 10 & 10 \\
\hline \multirow{2}{*}{ Precoital Interval (Days) \$ } & Mean & 3.5 & 3.9 & 4.5 & 4.5 \\
\hline & SD & 1.35 & 2.13 & 3.81 & 3.03 \\
\hline \multirow{2}{*}{ Gestation Length (Days) \$ } & Mean & 21.7 & 22 & 21.5 & 22.8 \\
\hline & SD & 0.48 & 0.47 & 0.71 & 0.42 \\
\hline No. littered & & 10 & 10 & 10 & 10 \\
\hline No. of live litters & & 10 & 10 & 9 & 10 \\
\hline Total No. of pups born & & 117 & 110 & 113 & 78 \\
\hline Mean litter size \$ & & 11.7 & 11 & 11.3 & 7.8 \\
\hline No. of pups dead at first observation & & 6 & 10 & 11 & 2 \\
\hline No. of pups alive on day 0 & & 111 & 100 & 102 & 76 \\
\hline No. of pups dead/cannibalized on day 1 & & 3 & 4 & 8 & 25 \\
\hline No. of pups alive on day 1 & & 108 & 96 & 94 & 51 \\
\hline No. of pups dead/cannibalized from day $2-4$ & & 0 & 9 & 15 & 5 \\
\hline No. of pups alive on day 4 & & 108 & 87 & 79 & 46 \\
\hline No. of pups discarded for standardization on day 4 & & 30 & 18 & 10 & 2 \\
\hline No. of pups alive after standardization on day 4 & & 78 & 69 & 69 & 44 \\
\hline No. of pups dead/cannibalized from day 5-13 & & 0 & 2 & 0 & 0 \\
\hline Mean viable litter size\$ & & 11.1 & 10 & 10.2 & 7.6 \\
\hline Live birth index (\%) & & 94.9 & 90.9 & 90.3 & 97.4 \\
\hline Sex ratio $(\%)$ & & 48 & 58.5 & 53.8 & 53.3 \\
\hline Day 4 survival index (\%) \# & & 97.3 & 87 & 77.5 & 60.5 \\
\hline No. of males paired with females & & 10 & 10 & 10 & 10 \\
\hline No. of females paired with males & & 10 & 10 & 10 & 10 \\
\hline No. of males siring a litter & & 10 & 10 & 10 & 10 \\
\hline No. of females impregnated (confirmed by vaginal plug/smear) & & 10 & 10 & 10 & 10 \\
\hline No. of females conceived/pregnant (confirmed at littering) & & 10 & 10 & 10 & 10 \\
\hline No. of dams used for corpora lutea and implantation count & & 10 & 10 & 10 & 10 \\
\hline No. of corpora lutea & & 130 & 122 & 125 & 90 \\
\hline No. of implantations & & 117 & 110 & 113 & 78 \\
\hline Male mating index (\%) \# & & 100 & 100 & 100 & 100 \\
\hline Male fertility index (\%) \# & & 100 & 100 & 100 & 100 \\
\hline Female mating index (\%) \# & & 100 & 100 & 100 & 100 \\
\hline Female fertility index (\%) \# & & 100 & 100 & 100 & 100 \\
\hline Mean No. of implantations $\$$ & & 11.7 & 11 & 11.3 & 7.8 \\
\hline Percentage of post-implantation loss $\$$ & & 5 & 9.5 & 15.5 & 2.9 \\
\hline
\end{tabular}

${ }^{\$}$ Compared by Levens, ANOVA and Dunnett's test after transformation $(\sqrt{ } x+1 / 2)$.

"Compared by ' $Z$ ' test.

Significantly lower than the vehicle control group.

the cube root of body weight of either sex at any of the doses tested (Figure 12).

\section{Areolae/nipple retention in pups}

The male pups did not exhibit areola/nipple retention on PND 13.

\section{Survival data of pups}

Significantly lower mean litter size and viable litter size was observed at $150 \mathrm{mg} / \mathrm{kg}$ bwt/day and it could be due to lower mean number of implantation. The Day 4 survival index were significantly 
lower at $150 \mathrm{mg} / \mathrm{kg}$ bwt/day dose due to the higher number of pups dead/cannibalized from Days 1-3 of lactation period. Mean oestrous cycle length in the treated groups was not significantly different from the vehicle and control group (Table 2).

\section{Fertility index}

The duration of gestation (gestation length), pre-coital time, fertility indices were not affected at any of the doses tested, when compared to vehicle control group. The mean number implantations were significantly lower at $150 \mathrm{mg} / \mathrm{kg}$ bwt/day dose, when compared to vehicle control, which in turn resulted in lower mean litter size (Table 2).

\section{Hormone analysis}

There were no significant changes observed in Thyroid Stimulating Hormone (TSH) and Thyroxin hormone (T4) levels in adult males (at termination), dams (on lactation Day 13) and pups (on Days 4 and 13 after birth) (Figure 13-16).

\section{Pathology}

There were no treatment related gross pathological changes in both parents and pups. There were no test item-related changes observed in the terminal body weights, organ weights and organ to body weight ratios in both sexes. No test item-related changes observed in thyroid gland weight of pups at all the dose levels tested.

There were no test item related histopathological in the reproductive organs in both males and females at all the doses tested. The staging of spermatogenesis did not reveal any stage specific changes at any of the doses tested. The spermatogenic cycle observed

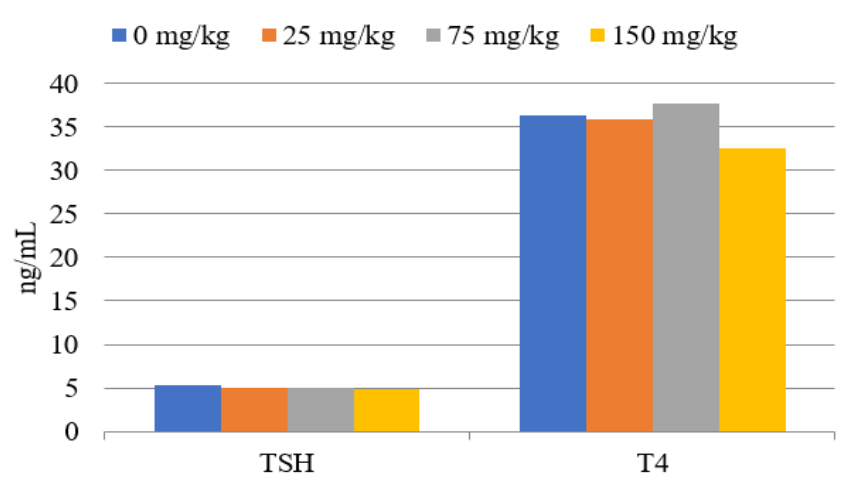

Figure 13: Thyroid hormone analysis in male rats at termination.

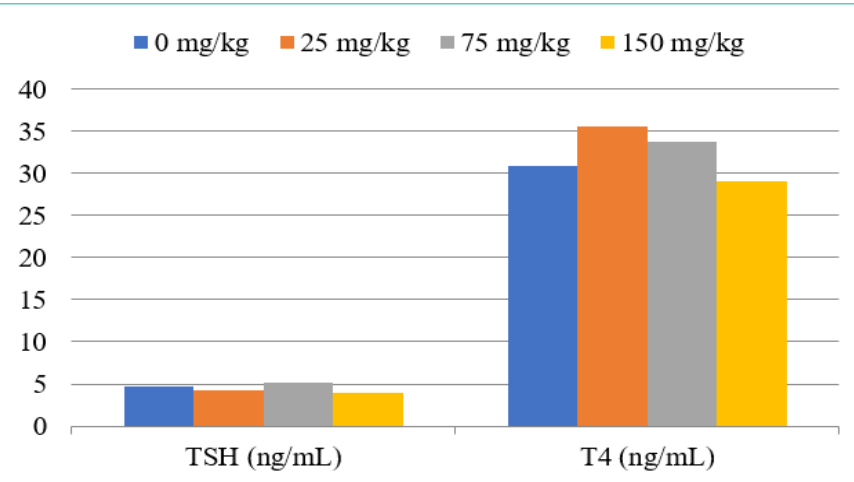

Figure 14: Thyroid hormone analysis in female rats on lactation day 13.
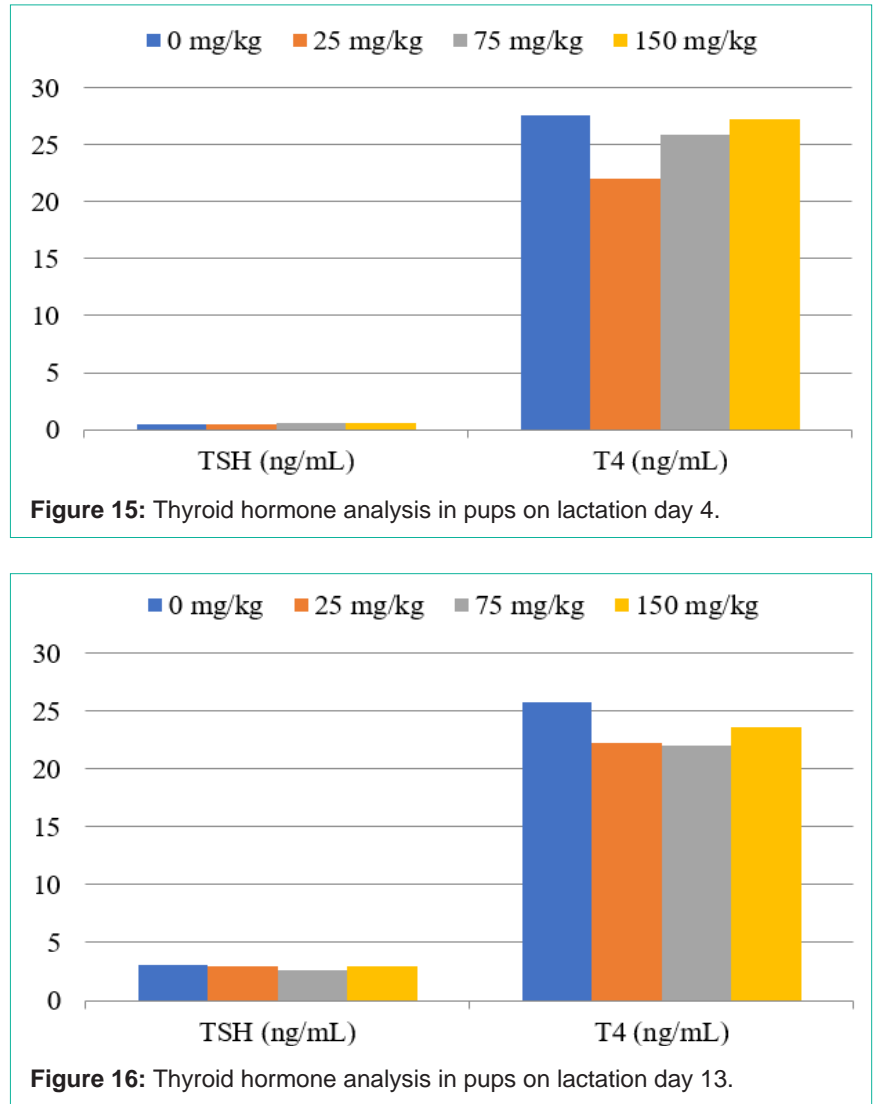

in the different seminiferous tubules of testes were complete and none of the stages of spermatogenesis was arrested in all the animals examined. Previous study findings also described no statistical difference was observed in sperm morphology, viability, motility or concentration, or in the sperm count [10]. There were no test itemrelated microscopic changes observed in thyroid gland of parents and pups.

All microscopic findings observed such as prostate (mononuclear cell infiltration) and thyroid gland (ectopic thymus in female rats and female pup, ultimobrachial cyst in male pup) were considered as a spontaneous findings normally found in this strain and species.

There were no external abnormalities were observed in live and dead pups at all the doses tested.

\section{Conclusion}

Daily oral (gavage) administration of TCS to male and female Wistar rats at dose levels of 25,75 and $150 \mathrm{mg} / \mathrm{kg}$ bwt/day for period of 28 days ( 2 consecutive weeks prior to mating, during mating and post mating period) for males or 2 weeks prior to mating, during mating, and during pregnancy until 13 days after delivery (females) did not induce any adverse effects on reproductive performance. The No Observed Adverse Effect Level (NOAEL) of TCS is considered to be $150 \mathrm{mg} / \mathrm{kg}$ bwt/day.

Considering the changes observed in the mean litter size, mean viable litter size, mean number of implantations and Day 4 survival index at $150 \mathrm{mg} / \mathrm{kg}$ bwt/day, the no observed adverse effect level (NOAEL)" for reproductive toxicity is considered to be $75 \mathrm{mg} / \mathrm{kg}$ bwt/ 
day.

\section{References}

1. Jones RD, Jampani HB, Newman JL, Lee AS. Triclosan: A review of effectiveness and safety in health care setting. Am J Infect Control. 2000; 28: $184-196$

2. Cooney CM. Triclosan comes under scrutiny. Environ Health Perspect. 2010; 118: 242.

3. SCCP (Scientific Committee on Consumer Products). OPINION ON Triclosan COLIPA n P32. 2009.

4. Jing JLJ, Yi TP, Bose RJC, McCarthy JR, Tharmalingam N, Madheswaran T. Hand Sanitizers: A Review on Formulation Aspects, Adverse Effects, and Regulations. Int J Environ Res Public Health. 2020; 17: 1-17.

5. EWG. Pesticide in Soap, Toothpaste and Breast Milk-ls it Kid Safe? Washington, DC: Environmental Working Group. 2008.

6. Dhillon SG, Kaur S, Pulicharla R, Brar KS, Cledon M, Verma M. Triclosan: Current Status, Occurrence, Environmental Risks and Bioaccumulation Potential. Int J Environ Res Public Health. 2015; 12: 5657-5684.

7. Calafat $A M, Y e X$, Wong AM, Reidy AM, Needham LL. Urinary Concentrations of Triclosan in the U.S. Population: 2003-2004. Environ Health Prospect. 2008; 116: 303-307.

8. Moss $\mathrm{T}$, Howes D, Williams FM. Percutaneous penetration and dermal metabolism of triclosan (2,4,4'-trichloro-2'- hydroxydiphenyl ether). Food Chem Toxicol. 2000; 38: 361-370.

9. Sandborgh-Englund G, Adolfsson-Erici M, Odham G, Ekstrand J. Pharmacokinetics of triclosan following oral ingestion in humans. J Toxicol Environ Health Part A. 2006; 69: 1861-1873.

10. Pernoncini KV, Montagnini BG, Marino de Goes ML, Garcia PC, Gerardin DCC. Evaluation of reproductive toxicity in rats treated with triclosan. Reprod Toxicol. 2018; 75: 65-72.

11. Wang X, Chen X, Feng X, Chang F, Chen M, Xia Y, et al. Triclosan causes spontaneous abortion accompanied by decline of estrogen sulfotransferase activity in humans and mice. Sci Rep. 2015; 15: 1-10.

12. Adolfsson-Erici M, Pettersson M, Parkkonen J, Sturve J. Triclosan, commonly used bactericide found in human milk and in the aquatic environment in Sweden. Chemosphere. 2002; 46: 1485-1489.

13. Allmyr M, Adolfsson-Erici M, McLachlan MS, Sandborgh-Englund G. Triclosan in plasma and milk from Swedish nursing mothers and their exposure via personal care products. The Science of the total environment. 2006; 372 87-93.

14. Toms LM. Triclosan in individual human milk samples from Australia. Chemosphere. 2011; 85: 1682-1686.

15. Dayan AD. Risk assessment of triclosan [Irgasan] in human breast milk. Food Chem Toxicol. 2007; 45: 125-129.

16. Wolff M, Teitelbaum S, Windham G, Pinney S, Britton J, Chelimo C, et al Pilot study of urinary biomarkers of phytoestrogens, phthalates, and phenols in girls. Environ Health Perspect. 2007; 115: 116-121.

17. Calafat AM, Ye X, Wong LY, Reidy JA, Needham LL. Urinary concentrations of triclosan in the U.S. population: 2003-2004. Environ Health Perspect. 2008; 116: 303-307.

18. Cullinan MP, Palmer JE, Carle AD, West MJ, Westerman B, Seymour GJ. The influence of a triclosan toothpaste on adverse events in patients with cardiovascular disease over 5-years. Sci Total Environ. 2015; 508: 546-552.

19. Gilles B, Benoit R, Olivier T, Virginie D, Barbara LB. Occurrence and toxicity of antimicrobial triclosan and by-products in the environment. Environ Sci Pollut R. 2012; 19: 1044-1065.

20. Von der Ohe PC, Jaroslav Slobodnik MSJ, Wemer Brack. Triclosan--the forgotten priority substance? Environ Sci Pollut Res. 2012; 19: 585-591.

21. SCCS (Scientific Committee on Consumer Safety) (2011) Opinion on Triclosan, SCCS/1414/11.
22. van Dijk A. 14C-Triclosan: Absorption, Distribution Metabolism and Elimination after Single/Repeated Oral and Intravenous Administration to Hamsters (RCC Project 351707), RCC Umweltchemie AG, Itingen/BL, Switzerland. 1994

23. van Dijk A. 14C-Triclosan: Absorption, Distribution, Metabolism and Elimination after Single/Repeated Oral and Intravenous Administration to Mice (RCC project no. 337781), RCC Umweltchemie AG, Itingen/BL, Switzerland. 1995.

24. van Dijk A. 14C-Triclosan: Absorption, Distribution and Excretion (ADE) after Single Oral and Repeated Oral Administration to Male Rats (RCC Project 341998), RCC Umweltchemie AG, Itingen/BL, Switzerland. 1996.

25. Lin YJ, Smith NL. Pharmacokinetics of Triclosan in Rats Following a Single Oral Administration, Colgate-Palmolive Company, Piscataway, New Jersey. 1990.

26. Park M, Kim S, Kim Y, Nam DJ, Ryoo JH, Lim S. Relationship between personal care products usage and triclosan exposure: the second Korean National Environmental Health Survey (KoNEHS 2012-2014). Ann Occup Environ Med. 2019; 31: 2.

27. Crofton KM, Paul KB, Devito MJ, Hedge JM. Short-term in vivo exposure to the water contaminant triclosan: evidence for disruption of thyroxine. Environ Toxicol Pharmacol. 2007; 24: 194-197.

28. Paul KB, Hedge JM, Bansal R, Zoeller RT, Peter R, DeVito MJ, et al Developmental triclosan exposure decreases maternal, fetal, and early neonatal thyroxine: a dynamic and kinetic evaluation of a putative mode-ofaction. Toxicology. 2012; 300: 31-45

29. Paul KB, Thompson JT, Simmons SO, Vanden Heuvel JP, Crofton KM Evidence for triclosaninduced activation of human and rodent xenobiotic nuclear receptors. Toxicol in Vitro. 2013; 27: 2049-2060.

30. Veldhoen N, Skirrow RC, Osachoff H, Wigmore H, Clapson DJ, Gunderson $\mathrm{MP}$, et al. The bactericidal agent triclosan modulates thyroid hormoneassociated gene expression and disrupts postembryonic anuran development. Aquat Toxicol. 2006; 80: 217-227

31. Axelstad M, Boberg J, Vinggaard AM, Christiansen S, Hass U. Triclosan exposure reduces thyroxine levels in pregnant and lactating rat dams and in directly exposed offspring. Food Chem Toxicol. 2013; 59: 534-540.

32. Yueh MF, Tukey RH. Triclosan: A widespread environmental toxicant with many biological effects. Annu Rev Pharmacol Toxicol. 2016; 56: 251-272.

33. Health Canada (Environment and Climate Change Canada Health Canada) (2016) Assessment Report Triclosan, Chemical Abstracts Service Registry Number 3380-34-5.

34. Zhang GX, Wang LL, Dong JY, Wei XY, Ding JC. Journal of Chongqing Medical University. 2013; 38: 1163-1168.

35. Zhou L, Tae HK, Kai SB, Xiao HC, Hyung SK. Triclosan exhibits a tendency to accumulate in the epididymis and shows sperm toxicity in male SpragueDawley rats. Environ Toxicol. 2015; 30: 83-91.

36. Kumar V, Chakraborty A, Kural MR, Roy P. Alteration of testicular steroidogenesis and histopathology of reproductive system in male rats treated with triclosan. Reprod Toxicol. 2009; 27: 177-185.

37. OECD Guideline No. 421 for testing of chemicals, Reproduction/ Developmental Toxicity Screening Test. 2016.

38. ILAR, Guide for the Care and Use of Laboratory Animals ( $8^{\text {th }}$ edition). National Research Council, Institute of Laboratory Animal Resources, National Academy Press, Washington, DC. 2011.

39. Gray Jr., LE, Ostby J, Monosson E, Kelce WR. Environmental antiandrogens: low doses of the fungicide vinclozolin alter sexual differentiation of the male rat. Toxicol Ind Health. 1999; 15: 48-64.

40. Shapiro SS, Wilk MB. An analysis of variance test for normality (complete samples). Biometrika. 1965; 52: 591-611.

41. Levene H. Robust tests for equality of variances. In: Olkin I, Ghurye SG Hoeffding W, Madow WG, Mann HB, editors. Contributions to probability and statistics. Stanford (CA): Stanford University Press. 1960: 278- 292. 
42. Kumar V, Balomajumder C, Roy P. Disruption of LH-induced testosterone biosynthesis in testicular leydig cells by triclosan: probable mechanism of action. Toxicology. 2008; 250: 124-131. 